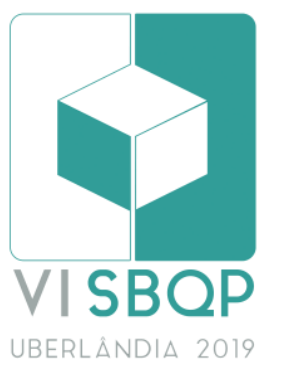

\title{
ARTICULANDO ENSINO, PESQUISA E EXTENSÃO: O URBANO SOB A LÓGICA DE RUAS COMPLETAS
}

\author{
ROSA, Ashiley Adelaide \\ Universidade Federal de Juiz de Fora, e-mail: ashiley.rosa@arquitetura.ufjf.br \\ LIMA, Fernando Tadeu de Araújo \\ Universidade Federal de Juiz de Fora, e-mail: fernando.lima@arquitetura.ufjf.br
}

\begin{abstract}
RESUMO
O presente artigo descreve os resultados de uma experiência didático-pedagógica desenvolvida por meio de uma disciplina de caráter extensionista e lecionada no último ano letivo, na Faculdade de Arquitetura e Urbanismo da Universidade Federal de Juiz de Fora (FAUUFJF). Nesta disciplina, intitulada "Projeto e Mobilidade Urbana", alunos da graduação trabalharam em grupos e desenvolveram proposições para a adequação das ruas Marechal Deodoro e Batista de Oliveira, na região central da cidade, na lógica das Ruas Completas. $O$ conceito de Ruas Completas busca redistribuir o espaço da rua de modo mais acessível, incentivando modos ativos de viagem e é também uma iniciativa que fortalece o comércio e identidade local. A metodologia de ensino empregada, se desenvolveu por meio das seguintes etapas: i) instrução e fundamentação teórica dos alunos para trabalhar com o conceito; ii) escolha das áreas a serem trabalhadas; iii) orientação e suporte para desenvolvimento das propostas dos alunos; e iv) apresentação das propostas para a sociedade, por meio de uma exposição. Com este trabalho pretende-se fortalecer a discussão sobre o tema, articular ensino, pesquisa e extensão universitária, e promover abordagens de ensino de projeto urbano que considerem mais especificamente a escala da rua, aspectos relacionados à caminhabilidade e que possam contribuir para a construção de uma cidade mais sustentável e equitativa.
\end{abstract}

Palavras-chave: Ensino de Arquitetura e Urbanismo, Mobilidade Urbana, Ruas Completas, Projeto Urbano.

\begin{abstract}
The present article describes the results of a didactic-pedagogical experience developed in an extensionist discipline and taught in the last school year in the Faculty of Architecture and Urbanism of the Federal University of Juiz de Fora (FAU-UFJF). In this discipline, entitled "Design and Urban Mobility", undergraduate students worked in groups and developed proposals for the adaptation of streets, Marechal Deodoro and Batista de Oliveira, in the downtown area, in the logic of Complete Streets. The Complete Streets concept seeks to redistribute street space in a more accessible way, encouraging active modes of travel and is also an initiative that strengthens trade and local identity. The teaching methodology employed was developed by the following stages: i) instruction and theoretical foundation of the students to work with the concept; ii) the choice of areas to be worked; iii) guidance and support for the development of student proposals; and iv) presentation of the proposals to the society, through an exhibition. This work intends to strengthen the discussion about the theme, to articulate teaching, research and university extension, and to promote approaches of teaching of urban project that consider more specifically the scale of the street, aspects related to the walkability and that can contribute to the construction of a more sustainable and equitable city.
\end{abstract}

Keywords: Teaching Architecture and Urbanism, Urban Mobility, Complete Streets, Urban Design.

ROSA, A.; LIMA, F. Articulando ensino, pesquisa e extensão: o urbano sob a lógica de Ruas Completas. In: SIMPÓSIO BRASILEIRO DE QUALIDADE DO PROJETO NO AMBIENTE CONSTRUÍDO, 6., 2019, Uberlândia. Anais... Uberlândia: PPGAU/FAUeD/UFU, 2019. p. 1480-1491. DOI https://doi.org/10.14393/sbqp19132. 


\section{INTRODUÇÃO}

Este artigo descreve uma experiência didático-pedagógica que visa a articular ensino, pesquisa e extensão, por meio de uma disciplina intitulada "Projeto e Mobilidade Urbana". Esta disciplina, se originou de um acordo de cooperação científica e de um projeto de extensão universitária firmados entre a Universidade Federal de Juiz de Fora (UFJF), a Frente Nacional dos Prefeitos (FNP), a Prefeitura de Juiz de Fora (PJF) e o instituto WRI Brasil. Esse convênio visou a dar suporte à elaboração e à implementação de projetos relacionados à Ruas Completas, bem como à disseminação de conhecimento, mediante a realização de disciplina de caráter extensionista, publicações, oficinas de trabalho, seminários, encontros e outros eventos correlatos. Na disciplina, alunos da Faculdade de Arquitetura e Urbanismo da Universidade Federal de Juiz de Fora (FAU-UFJF) trabalharam em grupos e desenvolveram proposições para a adequação de duas ruas da região central da cidade (Marechal Deodoro e Batista de Oliveira), na lógica das Ruas Completas.

A escolha das ruas Marechal Deodoro e Batista de Oliveira como objeto de estudo para os alunos da disciplina "Projeto e Mobilidade Urbana" se deu devido ao fato das mesmas serem foco de atenção da Prefeitura de Juiz de Fora (PJF), como possíveis alvos de intervenção dentro dos princípios de Ruas Completas.

Assim, a disciplina e seus resultados pretendem evidenciar e discutir sobre a importância de se ensinar e de se pensar uma cidade para os pedestres, em escala e qualidade apropriadas, em contrapartida ao atual crescimento dos centros urbanos, voltados ao expansionismo e à priorização do automóvel. Tal crescimento, para Gehl (2015), tem resultado em cidades planejadas sob o ponto de vista do veículo motorizado, negligenciando a escala humana e modais ativos e coletivos de transporte.

Neste contexto, o presente artigo apresenta-se da seguinte forma: i) uma breve revisão sobre a definição do conceito Ruas Completas, bem como um apontamento de sua inserção no contexto nacional e local; ii) uma descrição da experiência de ensino desenvolvida, relatando o desenho e os procedimentos didático-pedagógicos da disciplina proposta; iii) uma breve apresentação da experiência de uma pesquisa de pesquisa de mestrado que se articula com os conceitos e com as práticas adotadas na sala de aula; iv) uma descrição da experiência de extensão, de maneira a apresentar os pormenores sobre uma exposição com os resultados da disciplina e seus impactos na comunidade; e, por fim, v) uma apresentação das considerações finais e de uma discussão sobre o processo de projeto e sobre a dinâmica didático-pedagógica adotados.

\section{O CONCEITO DE RUAS COMPLETAS}

O conceito de Ruas Completas visa a permitir acesso e viagens seguros, atraentes e confortáveis para todos os usuários, sejam eles pedestres, ciclistas, passageiros ou motoristas e implica em uma redistribuição do espaço da rua, a partir do momento que trata de uma lógica de acomodação multimodal (LAPLANTE; MCCANN, 2008). 
Segundo a organização WRI Brasil (2017), esse conceito tem por finalidade alcançar que o espaço e a dinâmica das ruas sejam propostos de maneira mais democrática e que reflita a identidade do local onde se insere. 0 conceito de Ruas Completas (RC) é um conceito emergente no discurso de planejamento urbano e de transporte, que surgiu para expandir o foco do projeto das ruas, do automóvel para a acomodação de todos os modos de viagem e pessoas (MCCANN, 2013).

Em suma, segundo Barbara McCann (2010), as Ruas Completas podem ser amplamente definidas como ruas que tem como premissa acomodar com segurança e conforto a todos, independentemente do modo de viagem ou da habilidade do usuário.

No Brasil, esse conceito ganha maior visibilidade com a criação da Rede Nacional para a Mobilidade de Baixo Carbono (2017), que ampliou a disseminação e a implementação de projetos de Ruas Completas no país. Formada pela a Frente Nacional de Prefeitos, o WRI Brasil, e pelos municípios de Niterói, Porto Alegre, João Pessoa, Campinas, Joinville, Salvador, São Paulo, Juiz de Fora, Recife e Fortaleza, além do Distrito Federal, esta rede visa a proporcionar a troca de experiência entre as cidades, fomentando a adoção de práticas sustentáveis de mobilidade urbana e incentivando 0 desenvolvimento de projetos-piloto de Ruas Completas. Pretende-se, ainda, que o aprendizado e as experiências dessas iniciativas deem escala às práticas em diferentes regiões do país.

Neste cenário, a cidade de Juiz de Fora (MG), com um pouco mais de 564 mil habitantes, segundo o IBGE (2018) e situada na Zona da Mata Mineira, é um importante polo regional para os municípios circundantes e tem grande potencial para implementação de Ruas Completas, devido à sua participação na rede e à sua intenção de implementar um projeto-piloto pela prefeitura.

\subsection{Planejamento urbano na escala da rua}

A lógica de expansão urbana adotada atualmente e as políticas públicas para o desenvolvimento das cidades, orientadas prioritariamente para 0 automóvel, formam a base para o problema de mobilidade urbana atual. Desta maneira, trabalhar com medidas de incentivos para modos de deslocamento mais sustentáveis pode desviar gradualmente essa tendência à dependência do automóvel a curto e longo prazo (AL-MOSAIND, 2018).

Para Barbara McCann (2011), substituir o automóvel por modais alternativos de transporte não será suficiente para quebrar este ciclo, e será necessário, também, substituir a configuração espacial de nossas ruas. Em outras palavras, a inversão da concepção conceitual das ruas e do seu desenho são parte fundamental para uma mudança desse paradigma, ou seja, a busca por um desenvolvimento mais sustentável e equitativo das cidades pode começar por estratégias a partir da escala da rua.

Neste mesmo contexto, Lydon et al. (2012) afirmam que a melhoria da qualidade urbana das nossas cidades comumente começa na rua, no quarteirão, no passeio, ou ainda, no bairro. Essas intervenções, em menor dimensão física, são cada vez mais comuns e acabam por preparar a coletividade para investimentos maiores, além de permitir aos atores locais testar novos conceitos, como Ruas Completas. 


\section{A EXPERIÊNCIA DE ENSINO: A DISCIPLINA PROJETO E MOBILIDADE URBANA}

\subsection{Plano de aulas, procedimentos didáticos e a exposição}

A disciplina Projeto e Mobilidade Urbana, de caráter eletivo e fruto do convênio estabelecido, citado anteriormente, foi ofertada no primeiro e no segundo semestres do ano letivo de 2018, atendendo a cerca de 20 alunos por semestre. Esta disciplina foi lecionada pelos professores Fernando Lima e José Gustavo Francis Abdalla, da Faculdade de Arquitetura e Urbanismo (FAUUFJF) e teve como tutoras as mestrandas Ashiley Adelaide Rosa e Yane Almeida, do Programa de Pós-graduação em Ambiente Construído da Universidade Federal de Juiz de Fora (PROAC-UFJF).

Para dar início a disciplina, no primeiro semestre, foi realizada uma aula inaugural com a presença da analista de desenvolvimento urbano do instituto WRI Brasil, Luísa Peixoto, que por meio de uma palestra aberta ao público geral e aos alunos do curso (Figura 1), trouxe um pouco sobre o tema de Ruas Completas, estabelecendo para muitos o primeiro contato com esse conceito e abordagem de projeto.

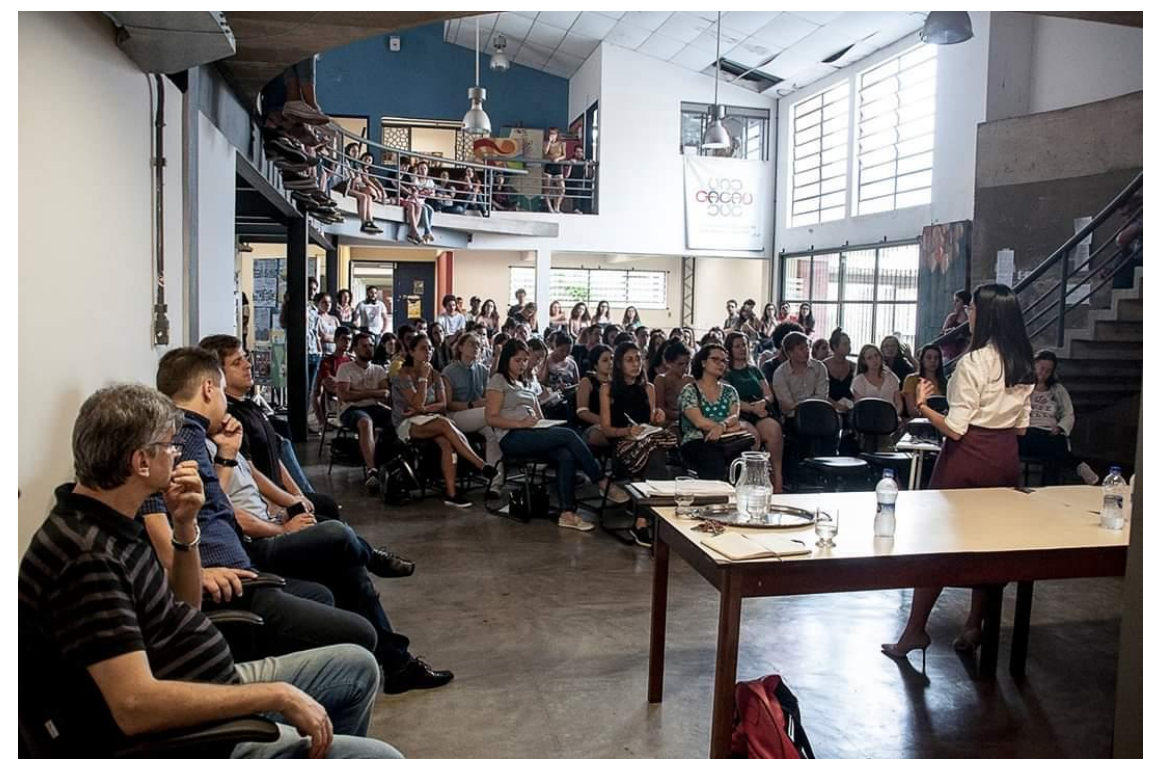

Figura 1 - Aula inaugural da disciplina

Fonte: Acervo DOMVS (2018)

Dado esse momento inicial com a palestra, o desenho da disciplina "Projeto e Mobilidade Urbana" se deu em três outros momentos, sendo eles: i) fundamentação teórica; ii) visita e diagnóstico do local a se desenvolver as propostas; e iii) ateliês de projeto e apresentação dos resultados intermediários e finais dos alunos por meio de seminário interno (Figura 2).

Dos procedimentos didáticos utilizou-se de aulas expositivas com apoio audiovisual, aulas práticas, visita a campo, orientações e ateliê para desenvolvimento do projeto. Para explicitar o conceito de Ruas Completas e seus desdobramentos no projeto urbano, foram temas abordados em sala de aula: i) vocações das ruas e o desenho viário; ii) a cidade que queremos; iii) o caminho dos pedestres e o caminho dos ciclistas; iv) o caminho do transporte coletivo e o caminho dos veículos privados, e; v) os elementos transversais a todos os usuários da rua. 


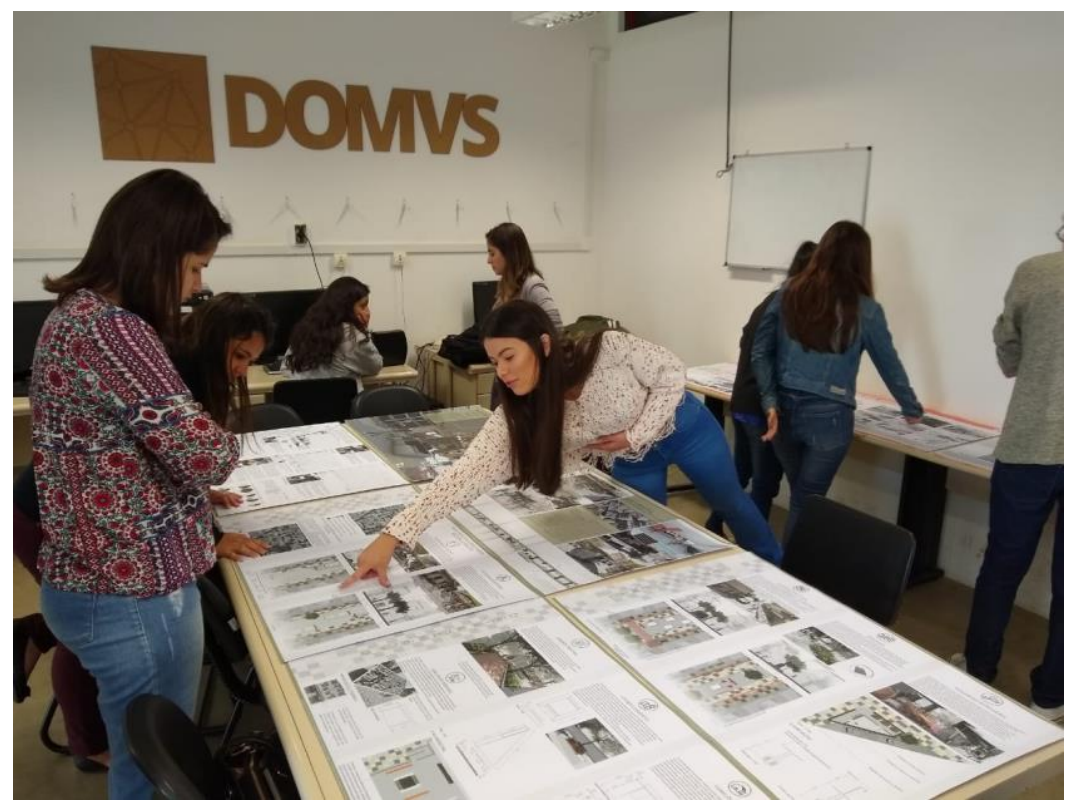

Figura 2 - Apresentação "Projeto e Mobilidade Urbana" Fonte: Fernando Lima (2018)

Ao final deste processo, os trabalhos desenvolvidos pelos alunos, foram expostos em um local de acesso público e gratuito, a fim de promover a discussão sobre as propostas, e partilhar com os gestores e atores do ambiente construído novas ideias para a mobilidade urbana. Além de possibilitar o acesso por parte dos cidadãos e transeuntes da rua Marechal Deodoro, local da proposta e exposição, o acesso facilitado à informação e às propostas desenvolvidas sob a lógica de Ruas Completas. Esta exposição será alvo de especial atenção em seção posterior e específica deste paper.

\section{A EXPERIÊNCIA DE PESQUISA: INTEGRAÇÃO COM O MESTRADO EM AMBIENTE CONSTRUÍDO}

O desenvolvimento da disciplina contou com contributos de uma pesquisa de Mestrado em Ambiente Construído, em andamento, da mestranda Ashiley Adelaide Rosa, do PROAC-UFJF, que abarca o conceito de Ruas Completas como objeto de estudo e busca desenvolver uma ferramenta de análise de impacto para essa abordagem de projeto urbano.

Tal dinâmica permitiu que por meio de um estágio de docência, a mestranda estivesse envolvida e presente nas aulas e que se construísse uma relação direta da temática de sua pesquisa com a prática de ensino. Da mesma forma, foi possível perceber o fluxo inverso, de maneira que a experiência com os alunos em sala de aula trouxe muitos contributos para a pesquisa. Neste cenário, houve o fortalecimento e a retroalimentação das práticas de pesquisa e de ensino, ampliando as discussões e as definições sobre o conceito, além de possibilitar maior suporte aos alunos nas orientações dentro e fora da sala de aula.

\section{A EXPERIÊNCIA DE EXTENSÃO: A EXPOSIÇÃO "JUIZ DE FORA PARA AS PESSOAS"}

Com o objetivo principal de trazer a comunidade local para a discussão sobre a cidade, bem como de levar o conhecimento produzido na Universidade 
para além de seu muros, foi realizada uma exposição entre os dias 14 de março a 10 de maio deste ano (2019), no Espaço Cultural dos Correios, na cidade de Juiz de Fora - MG. O local da exposição situa-se em uma das ruas do recorte urbano das propostas, a rua Marechal Deodoro, o que permitiu o acesso facilitado dos usuários diretos das ruas aborcadas pelos alunos. Durante o período de visitação mais de 400 pessoas estiveram na exposição, que obteve ampla divulgação na mídia local.

A organização foi concentrada e coordenada pelo Laboratório de Investigação em Arquitetura e Urbanismo (DOMVS), da Faculdade de Arquitetura e Urbanismo (FAU-UFJF). Houve, também, a participação dos outros parceiros do convênio, a saber: a Secretaria de Transporte e Trânsito de Juiz de Fora (SETTRA), a Pró-Reitoria de Extensão da Universidade Federal de Juiz de Fora (PROEX), o instituto WRI Brasil, a Frente Nacional dos Prefeitos (FNP), o Programa de Pós-Graduação em Ambiente Construído (PROAC-UFJF), entre outros que colaboraram na concepção, na elaboração e na execução da exposição.

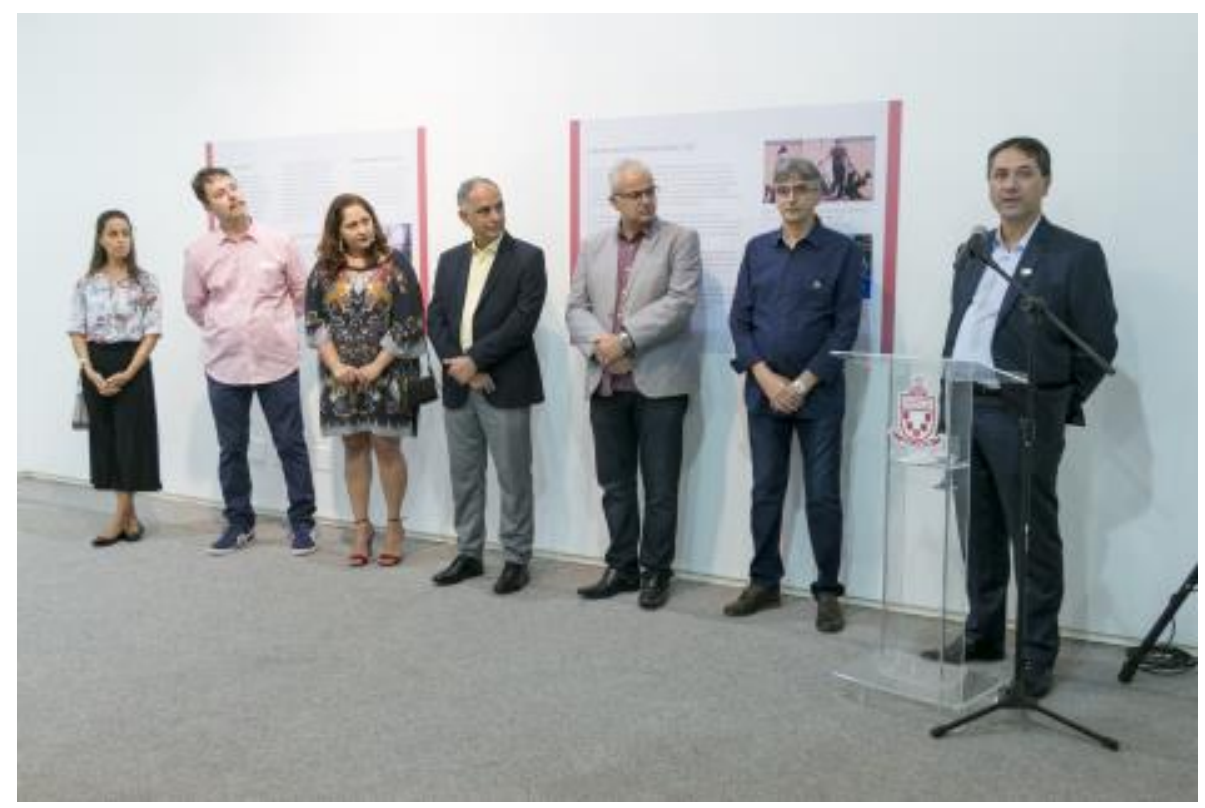

Figura 3 - Evento de abertura da exposição

Fonte: Daniel Hunter/WRI Brasil (2019)

A cerimônia de abertura da exposição (Figura 3), contou com a presença de cerca de 80 pessoas, entre elas: o prefeito da cidade de Juiz de Fora, Antônio Almas; o reitor da Universidade, Marcus Vinicius David; a pró-reitora de extensão, Ana Lívia de Souza Coimbra; a representante do WRI Brasil, Ariadne Samios; além dos professores da disciplina, Fernando Lima e José Gustavo Francis Abdalla, que também são coordenadores do projeto de extensão e respectivamente, vice-diretor e diretor da Faculdade de Arquitetura e Urbanismo (FAU-UFJF).

Foram expostos os trabalhos dos alunos que cursaram a disciplina "Projeto e Mobilidade Urbana" no ano de 2018 ( $1^{\circ}$ e $2^{\circ}$ semestres), contabilizando dezenove alunos-expositores e quatro propostas de projeto apresentadas (Figuras 4 e 5). Houve também painéis com materiais explicativos do WRI Brasil, da SETTRA, e da PROEX (Figura 6), que apresentaram as suas atribuições e contribuições para com o convênio e outras iniciativas desenvolvidas, a fim de 
fomentar a exposição como um ambiente de ensino-aprendizagem, de discussão da cidade e de dispersão de novos conceitos e ideias.
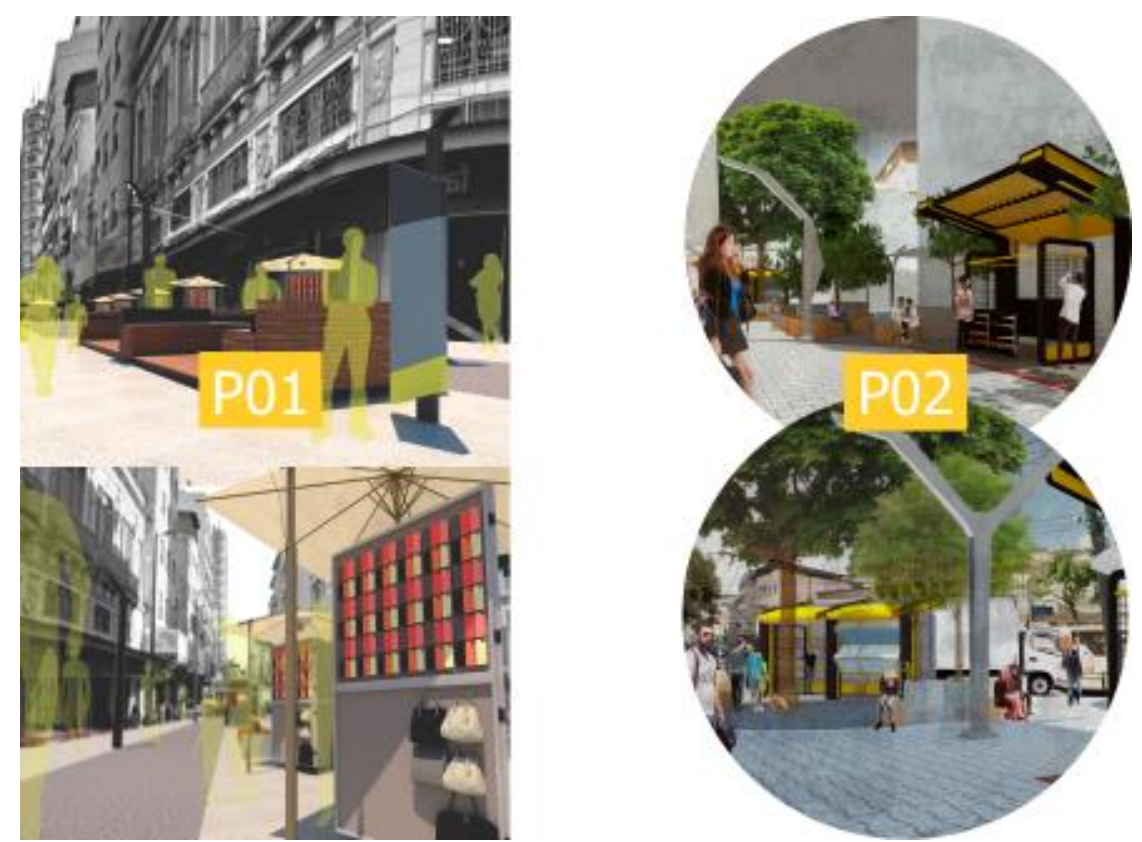

Figura 4 - Detalhes das propostas dos alunos do primeiro semestre Fonte: Dos autores (2019)
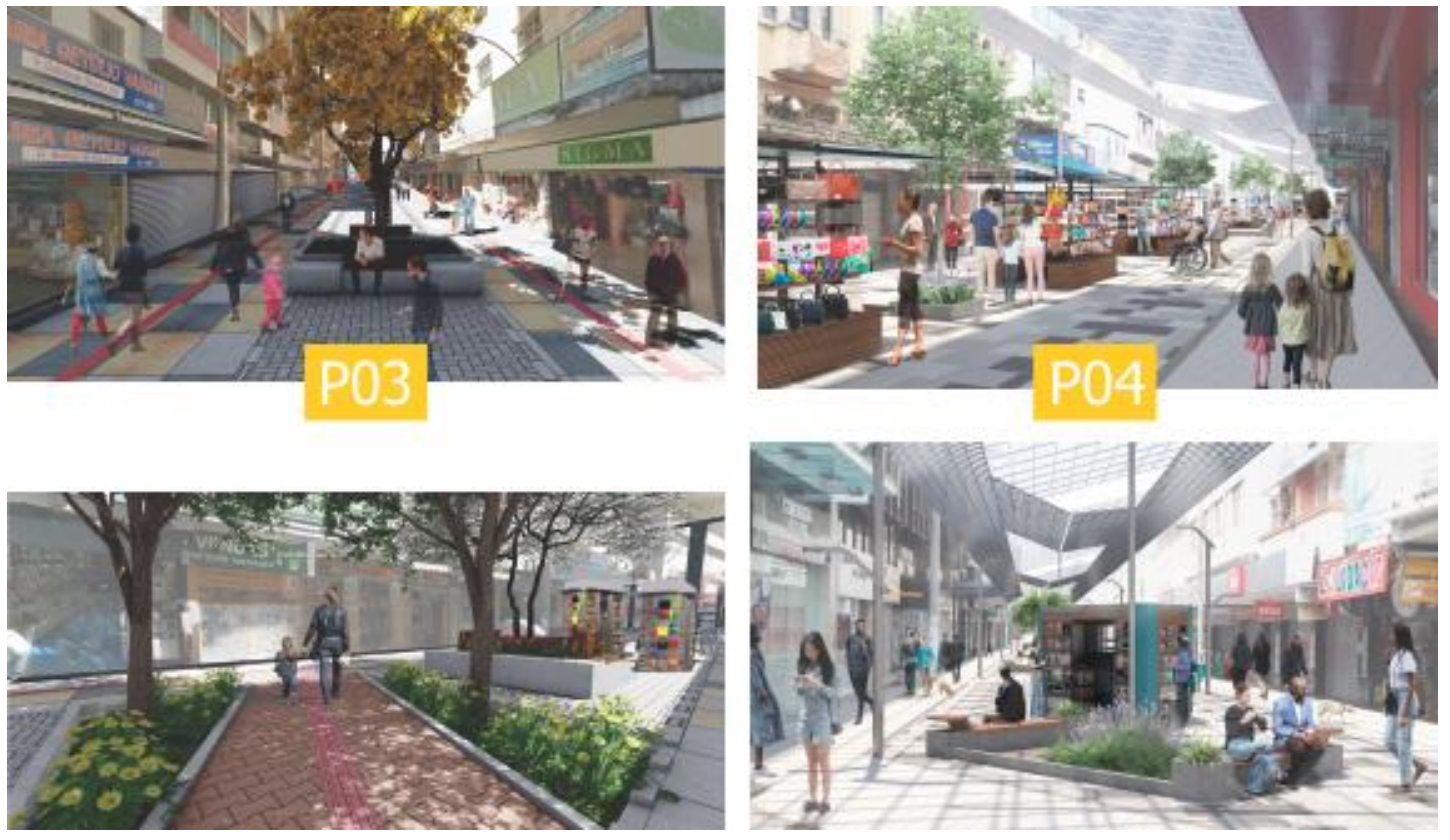

Figura 5 - Detalhes das propostas dos alunos do segundo semestre Fonte: Dos autores (2019)

Para as propostas em especifico, teve-se o cuidado nas orientações em sala de aula para que o produto final, os painéis da exposição, tivessem uma linguagem acessível a todo público potencial, mas que ao mesmo tempo alcançasse um alto nível de detalhamento dos mobiliários, paginação, drenagem, vegetação, dentre outros aspectos do projeto, que possibilitassem a sua compreensão em totalidade, do macro ao micro, explorando de cada grupo as suas potencialidades e diferenciais. 


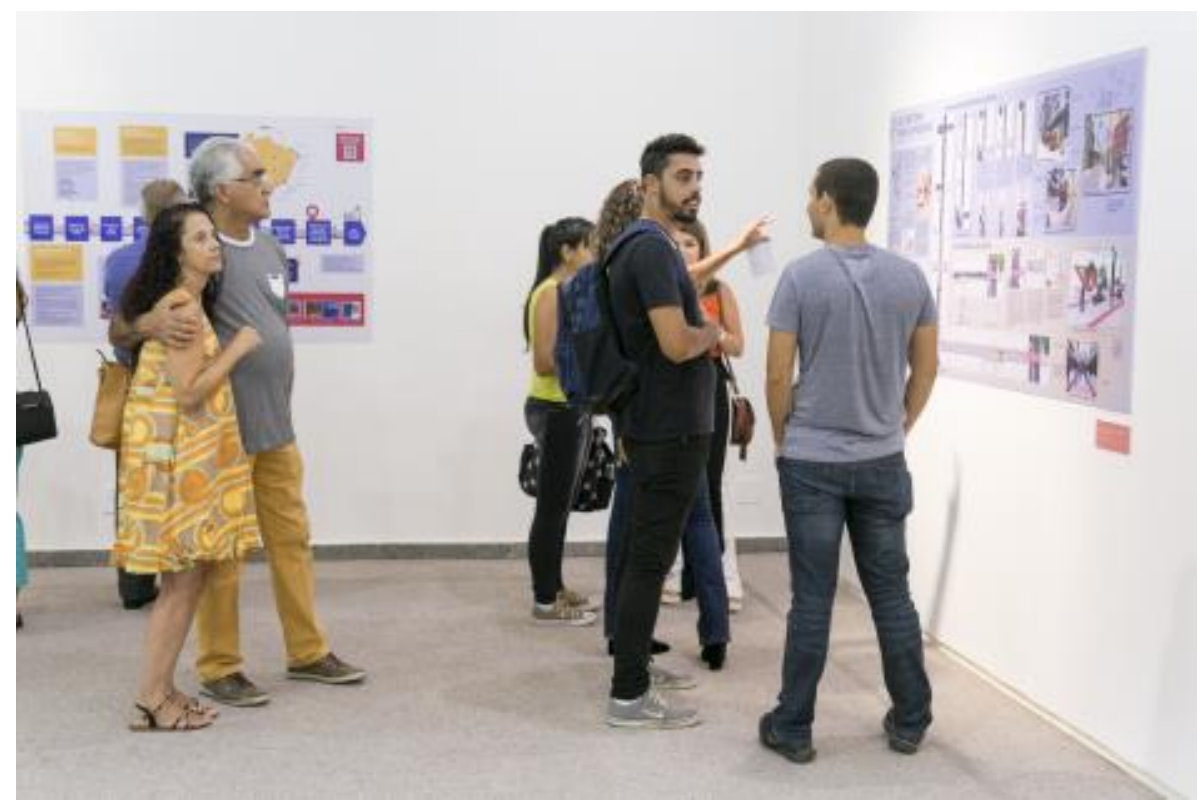

Figura 6 - A exposição

Fonte: Daniel Hunter/WRI Brasil (2019)

\subsection{Avaliação dos trabalhos acadêmicos}

Tendo em vista a importância da participação dos usuários na concepção dos projetos, as propostas expostas pelos alunos foram avaliadas por meio de uma consulta pública. A ideia aqui era poder perceber as impressões que a população tem sobre o uso das ruas e as propostas desenvolvidas. Portanto, no local da exposição havia uma urna (Figura 7) e cédulas (Figura 8) para que os visitantes pudessem avaliar cada uma das propostas com notas de 0 (zero) a 10 (dez), e também, colocar seus comentários sobre os projetos e a exposição como um todo. Cada proposta possuía sua legenda, logo abaixo do painel, para que o visitante-avaliador pudesse identificar a numeração da proposta, bem como seus autores e participar da pesquisa de opinião.

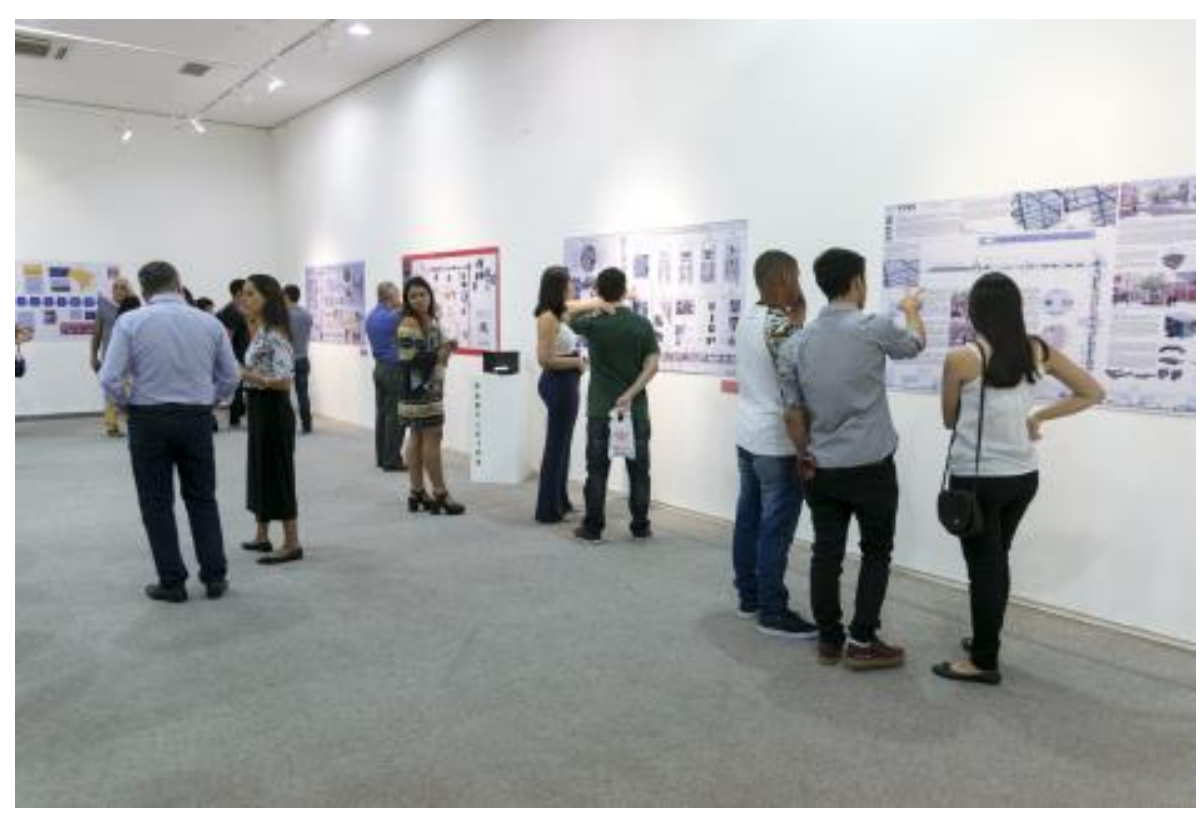

Figura 7 - A urna e propostas em avaliação Fonte: Daniel Hunter/WRI Brasil (2019) 




Figura 8 - Modelo da cédula de avaliação das propostas em exposição Fonte: Dos autores (2019)

As avaliações permitiram captar um pouco dos anseios e predileções por parte das pessoas que conhecem e utilizam as ruas Marechal Deodoro e Batista de Oliveira. Como síntese das 58 cédulas recolhidas pôde-se obter um gráfico com a recorrência das notas (Gráfico 1) e outro com a média das notas obtidas para cada proposta (Gráfico 2). Os resultados da pesquisa de opinião pública demostraram as propostas com maior aceite dos usuários, e ao mesmo tempo, a qualidade dos projetos apresentados. Somado a essa avaliação, obteve-se alguns comentários, que em sua maioria demostraram satisfação com os resultados e gratificação pela iniciativa da disciplina em extrapolar os limites físicos da Universidade.

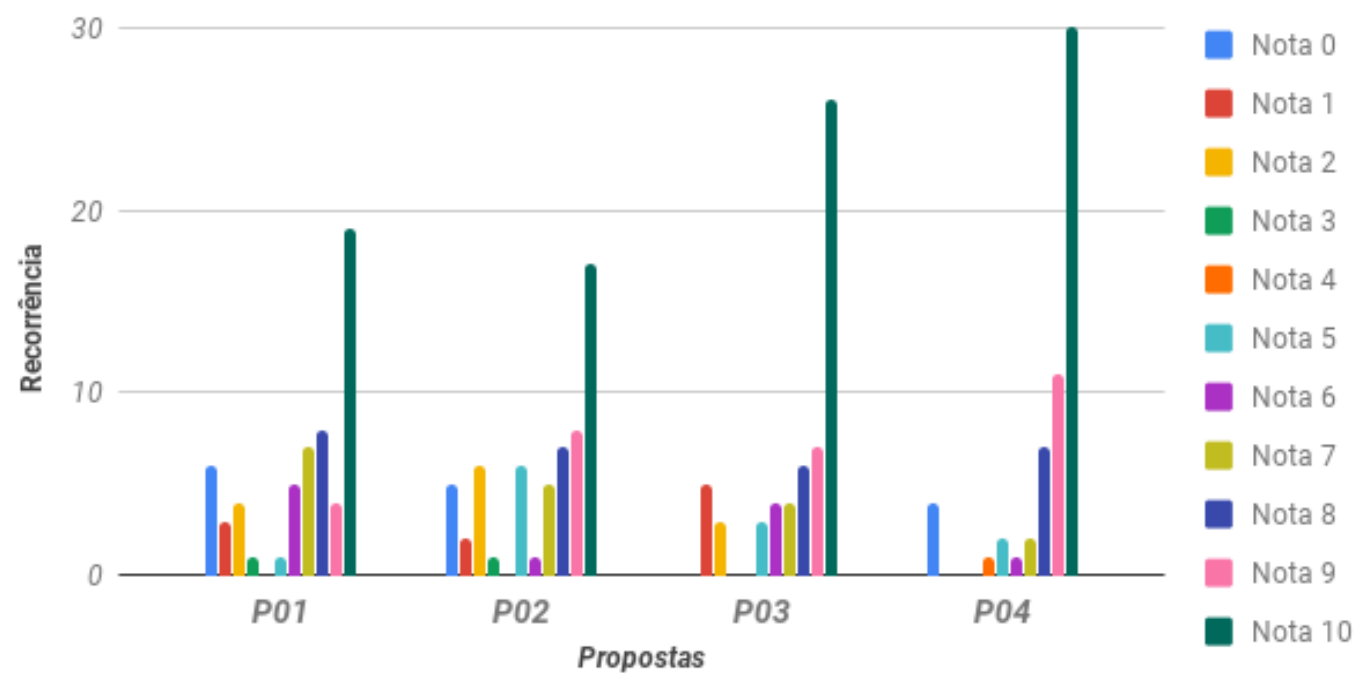

Gráfico 1 - Recorrência das notas da avaliação das propostas de projeto Fonte: Dos autores 


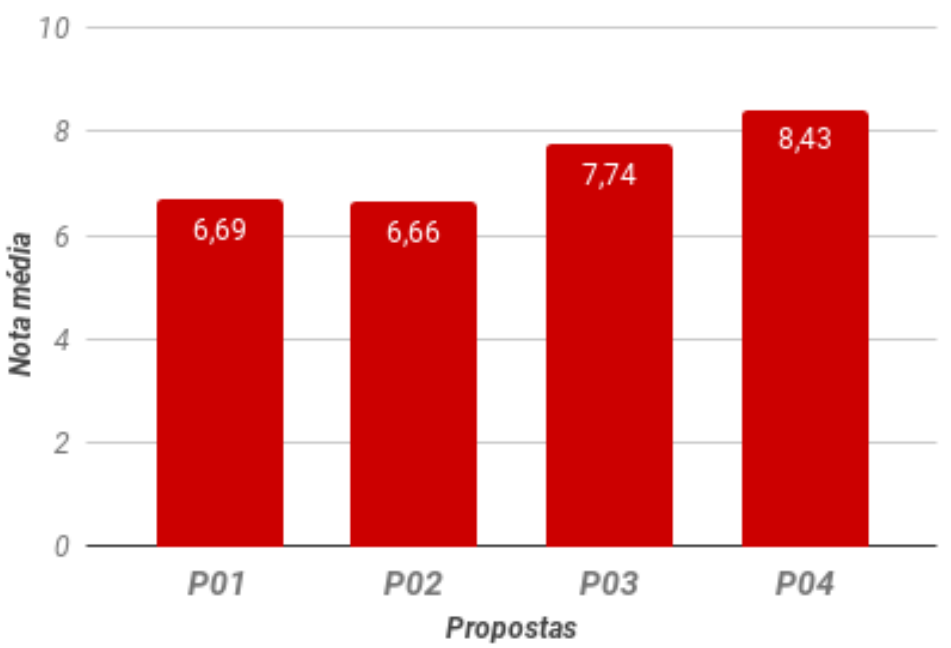

Gráfico 2 - Média das notas da avaliação por proposta de projeto Fonte: Dos autores

\subsection{Articulação da intervenção externa com a exposição: Urbanismo Tático na Rua Marechal Deodoro}

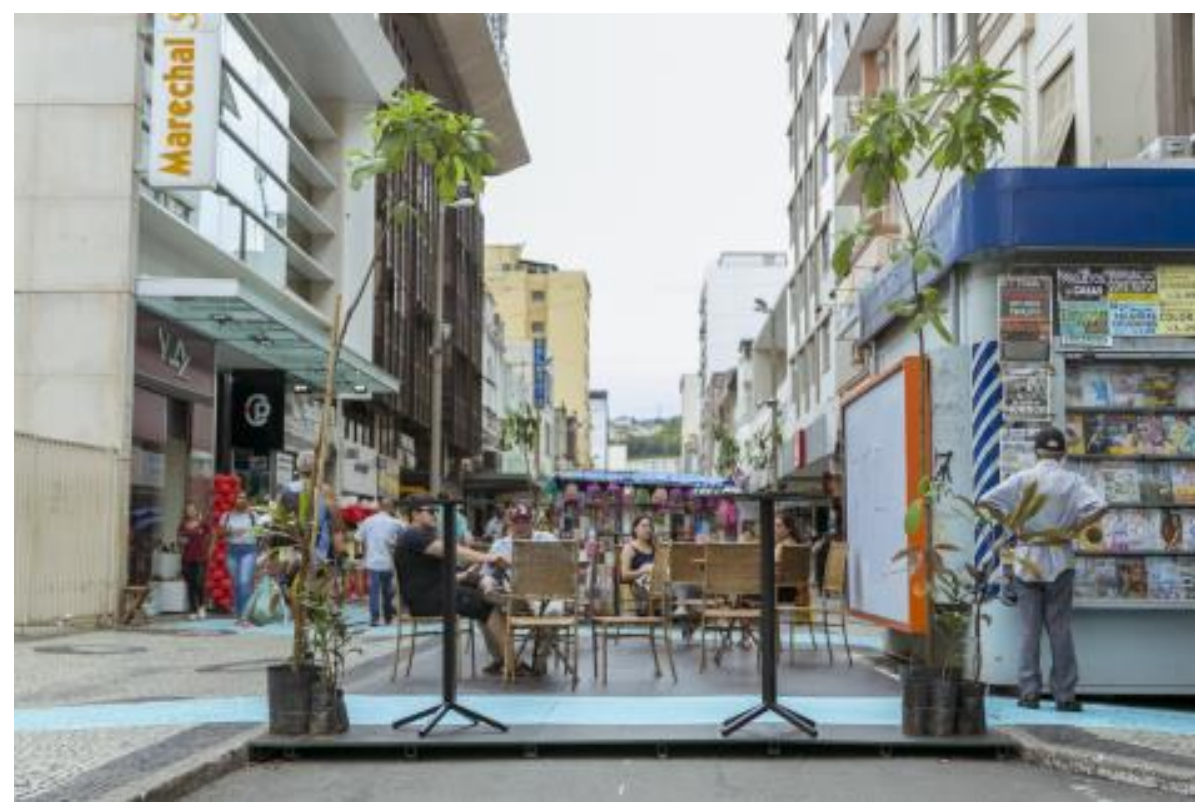

Figura 9 - Intervenção temporária R. Marechal Deodoro, Juiz de Fora/MG.

Fonte: Daniel Hunter/WRI Brasil (2019)

Concomitante à abertura da exposição, a rua Marechal Deodoro amanheceu diferente, devido à realização de uma intervenção de urbanismo tático (Figura 9), e premissas de Rua Completa. A rua em questão teve o tráfego de veículos interditado e os vendedores informais, ambulantes, que antes ficavam nas calçadas, dificultando a passagem do pedestre, foram direcionados ao centro da rua. Foram colocados tablados no centro da rua para configurar espaços de estar e descanso em uma área efervescente da cidade. Essa ação foi desenhada para acontecer no dia de lançamento da exposição e resultou em um grande impacto nos usuários pela transformação de um pequeno trecho da rua. Além disso, trouxe grande visibilidade à exposição e ao tema estudado, despertando interesse dos transeuntes e atraindo grande parte da mídia local para divulgação do projeto. Embora, esta ação tenha 
sido coordenada de maneira mais direta pela SETTRA, ela também contou com a participação de alunos da Faculdade de Arquitetura e Urbanismo (FAU-UFJF) tanto na etapa de projeto, quanto na execução como voluntários, que fora realizada na madrugada anterior.

\section{CONSIDERAÇÕES FINAIS}

A criação e a implementação da disciplina proposta resultou na utilização de uma nova abordagem, que permitiu considerar demandas locais e globais, além de abordar aspectos sociais, econômicos, ambientais e os problemas gerados pelo crescimento populacional e territorial das cidades. Foi possível, também, o desenvolvimento de propostas que visaram a priorizar o pedestre e uma nova lógica de organização de nossas ruas e de nossos centros urbanos. Além disso, a iniciativa aqui descrita, permitiu aproximar o conhecimento produzido na Universidade da população em geral. Neste contexto, espera-se que esta experiência didático-pedagógica estimule outras instituições de ensino a se lançarem no mesmo desafio, e a participar de maneira cada vez mais efetivas nas discussões sobre mobilidade urbana de suas respectivas cidades, bairros e ruas.

Ressalta-se aqui também a importância da articulação entre ensino, pesquisa e extensão nas instituições de ensino superior, como uma estrutura que se retroalimenta em busca de alcançar mais pessoas e com mais qualidade no que se propõe a oferecer, principalmente, um ensino de qualidade.

\section{AGRADECIMENTOS}

Os autores gostariam de agradecer à Universidade Federal de Juiz de Fora e à Coordenação de Aperfeiçoamento de Pessoal de Nível Superior (CAPES) pelo apoio recebido para o desenvolvimento da pesquisa. Agradecemos também ao Programa de Pós-Graduação em Ambiente Construído (PROAC-UFJF) pelo suporte financeiro à apresentação deste trabalho. Agradecemos, ainda, à Prefeitura de Juiz de Fora (PJF), ao WRI Brasil e à Frente Nacional dos Prefeitos (FNP) pelo convênio estabelecido e pelo apoio nas atividades elaboradas. Por fim, agradecemos de maneira especial ao professor José Gustavo Francis Abdalla, à tutora Yane Almeida e a todos os alunos e alunas que se envolveram na disciplina e na exposição aqui relatadas.

\section{REFERÊNCIAS}

AL-MOSAIND, M. Applying complete streets concept in Riyadh, Saudi Arabia: opportunities and challenges. Urban, Planning and Transport Research, v. 6, n. 1, p. 129-147, 2018.

GEHL, J. Cidade para Pessoas. Tradução Anita Di Marco, $3^{a}$ ed. São Paulo: Perspectiva, 2015.

IBGE. Instituto Brasileiro de Geografia e Estatística. Projeção da População:

Revisão 2018. In: IBGE, 2017. Disponível em

<https://cidades.ibge.gov.br/brasil/mg/juiz-de-fora/panorama>. Acesso em 20 fev. 2019.

LAPLANTE, J.; MCCANN, B. Complete Streets: We Can Get There from Here. ITE Journal, v. 78, n. 5, p. 24-28, 2008. 
LYDON, M. et al. Tactical Urbanism: Short-term Action, Long-term Change. Street Plans Collective. [S.I: s.n.], 2012. Disponível em:

<https://issuu.com/streetplanscollaborative/docs/tactical_urbanism_vol.1>. Acesso em: 20 fev. 2019.

MCCANN, B. Completing our streets: The transition to safe and inclusive transportation networks. Washington, DC: Island Press, 2013.

McCANN, B. Perspectives from the field: Complete Streets and Sustainability. Environmental Practice, v. 13, n. 1, p. 63-64, 2011. Disponível em:

<https://www.cambridge.org/core/article/perspectives-from-the-fieldcomplete-streets-and-sustainability/36B53D4FFE5E4564BAEDB63929F01511>.

MCCANN, Barbara. Happy Anniversary, Complete Streets! In: Smart Growth America, 2010. Disponível em: <https://smartgrowthamerica.org/happyanniversary-complete-streets/>. Acesso em: 21 mar. 2019.

NATIONAL COMPLETE STREETS COALITION (NCSC). What are complete streets? In: Smart Growth America, 2019. Disponível em: <

https://smartgrowthamerica.org/program/national-complete-streets-

coalition/publications/what-are-complete-streets/>. Acesso em 20 fev. 2019.

WRI BRASIL. Afinal, o que são Ruas Completas? In: WRI Cidades, 2017. Disponível em: <http://wricidades.org/noticia/afinal-o-que-sao-ruas-completas>. Acesso em 10 jan. 2019. 